\section{Charitable Giving (Peter Singer)}

Pablo Stafforini

Centre for Effective Altruism, Oxford, UK

\section{Synonyms}

Author; Donations; Morality; Philosopher

\section{Definition}

According to Peter Singer, people in affluent societies have a strong moral obligation to donate much, if not most, of their resources to charitable organizations that prevent death and suffering.

\section{Introduction}

Most of us believe that morality requires that we give, at best, a modest amount to charity. Giving beyond this requirement may be morally admirable but is not morally obligatory. In an influential early paper (Singer 1972), and numerous subsequent publications (Singer 1999, 2009, 2011), the Australian philosopher Peter Singer has challenged this widespread view. According to Singer, people in affluent societies - including academics reading these lines - have a strong moral obligation to donate much, if not most, of their resources to charitable organizations that prevent death and suffering.

To support his conclusion, Singer appeals to two separate arguments: an argument involving an analogy between particular cases (the argument from analogy) and an argument from general philosophical principles (the basic argument).

\section{The Argument from Analogy}

The argument from analogy, sketched in Singer's original paper and developed more recently by Singer and others (Unger 1996), invites us to consider our intuitive responses to the following scenario:

The Pond. As you walk past a shallow pond, you see a child drowning in it. If you wade in, your expensive suit will be ruined. If you don't, the child will die. Should you wade in?

Nearly everyone agrees that you are morally required to wade in. But consider, next, a different scenario:

The Letter. You receive a letter from a charitable organization. The letter asks you to donate an amount sufficient to prevent a child from dying. This amount is equivalent to the cost of an expensive suit. Should you donate?

Here most people believe that you aren't morally required to donate.

According to the argument from analogy, these different responses are unjustified. If we believe 
that we should wade in and save the child in the Pond, even at the expense of ruining an expensive suit, we should also believe that we should make the donation and save the child in the Letter, at a comparable cost.

Critics of Singer have resisted the challenge by attempting to identify a relevant disanalogy between the two cases (Ashford 2011). Thus, some critics have pointed out that the child in the Pond is a member of our community, while the child in the Letter case isn't. Morality requires that we assist our compatriots, but it doesn't issue a similar requirement to help foreigners. One could imagine, however, a variant of the Pond in which the child drowning isn't a member of our community, and it seems that most people would still judge that morality requires that you rescue her.

Other critics have pointed out that only you can save the child in the Pond, whereas many others could in principle save the child in the Letter. But again, the details of the Pond may be slightly altered, to yield a variant where there are other individuals in a position to wade in. Supposing that these bystanders decide not to intervene, most people would agree that, just like in the original case, you are morally required to save the child.

Finally, critics have pointed out that, unlike the Pond, where we know that the child will be saved if we take action, the Letter involves considerable uncertainty surrounding the effects of our actions. It seems reasonable to be skeptical, given the lack of relevant information about the charity and the complex causal chain involved. Still, here, too, one can tweak the details and stipulate that the charity has an impeccable track record of effectiveness so that we can realistically expect our donation to have its intended effect. (As will be seen in the next section, such a stipulation is not unrealistic.) Yet even after these adjustments, most people persist in thinking that you are morally required to donate in one case but not in the other.

More generally, for any alleged disanalogy claimed to justify our different moral attitudes toward the two cases, Singer's strategy is to alter the details of one of the cases in such a way that this new pair of cases (1) no longer exhibits the disanalogy and yet (2) continues to elicit the same moral attitudes as the original pair.

\section{The Basic Argument}

Singer's basic argument consists of three premises:

First premise: We are morally required to prevent something very bad from happening if we can do so without thereby sacrificing anything of comparable moral importance.

Second premise: Death and suffering are very bad. Third premise: We can prevent death and suffering without sacrificing anything of comparable moral importance.

From these three premises, Singer draws the conclusion that we are morally required to give much, if not most, of our money to charitable organizations that prevent death and suffering.

The second premise is uncontroversial, at least with respect to pain: even philosophers, who disagree with each other on just about everything, agree that (unwanted, undeserved) pain is intrinsically bad. The third premise may have been somewhat controversial back when Singer first presented his argument. At the time, it was hard to know what an individual could accomplish by donating a given amount of money to a charitable organization. This is no longer the case, however. GiveWell, a highly respected charity evaluator, estimates that a donation of about $\$ 3000$ to the Against Malaria Foundation will, in expectation, prevent a child from dying of malaria (GiveWell 2015). For people in affluent societies, giving \$3000 doesn't involve a sacrifice of comparable moral importance to saving a child's life.

Consider, finally, the first premise. It, too, seems relatively uncontroversial. It only requires us to prevent what is bad rather than to promote what is good, and subjects this requirement to the proviso that the agent shouldn't be asked to sacrifice something of comparable moral importance. Furthermore, the premise could be significantly weakened, to require us to prevent something very bad from happening if we can do so without thereby sacrificing anything morally significant (Singer 1972, p. 231). Such a weakened principle 
would be even less controversial but would still issue very demanding requirements.

When considered in isolation, each of the premises thus appears plausible. Yet they jointly imply a conclusion that contradicts what most of us believe. In fact, Singer thinks that this conclusion is so radical that "the whole way we look at moral issues [...] needs to be altered, and with it, the way of life that has come to be taken for granted in our society" (Singer 1972, p. 230).

In response, some philosophers have argued that morality cannot demand so much from us and that therefore Singer's conclusion must be mistaken. As David Lewis remarked in discussing a variant of Singer's original argument, "even if we cannot diagnose the flaw, it is more credible that the argument has a flaw we cannot diagnose than that its most extreme conclusion is true" (Lewis 2000, p. 155) This response, however, assumes that we are justified in believing that morality is not as demanding as Singer's conclusion implies. Other philosophers have disputed this assumption (Sobel 2007).

\section{Explaining Our Responses}

As we have seen, Singer argues that our different responses to the Pond and the Letter are unjustified. A separate question concerns the explanation of these responses, to which we now turn.

Considerable progress has been made in the study of moral judgment and decision-making in recent years (Bartels et al. 2015). Perhaps the most influential account in the literature is Joshua Greene's dual-process theory of moral judgment (Greene 2014a). On this theory, the same contrast between implicit unconscious processes (System 1) and explicit conscious processes (System 2) that explains our thinking in most domains (Kahneman 2011) also explains our moral thinking. Situations involving "up-close-and-personal" interaction, of the sort our ancestors in the environment of evolutionary adaptedness would have encountered on a regular basis, trigger rapid, unconscious responses. By contrast, situations involving distant, impersonal interaction trigger slow, conscious responses. Greene's dual-process theory could thus explain people's responses to the Pond and the Letter as resulting from the operation of these two cognitive subsystems.

This scientific explanation may have philosophical implications. So-called debunking explanations seek to undermine the justification of a belief by tracing back its causal origins to an unreliable process of belief formation (Kahane 2011). As Greene notes, "science may teach us that some of our judgments are sensitive to features that, upon reflection, do not seem to matter morally" (Greene 2016, p. 176). As an example, consider incest. Once we understand our negative responses to the thought of sexual intercourse between close family members as originating in selective pressures to avoid birth defects, we may cease to believe that incest is inherently morally wrong.

We may similarly be inclined to distrust our belief that there is a fundamental moral difference between the Pond and the Letter. If Greene's account is correct, these two situations trigger different responses as a result of a historical accident. We feel that there is a strong moral obligation to save the child in one scenario, but not in the other, because in the environment of evolutionary adaptedness it was possible to help others in personal ways, like wading into ponds, but not in impersonal ways, like donating money. Singer himself favors this sort of debunking explanation. He writes: "What is the moral salience of the fact that I have killed [or saved] someone in a way that was possible a million years ago, rather than in a way that became possible only two hundred years ago? I would answer: none" (Singer 2005, p. 348).

One response to this argument is to challenge the scientific premise on which it rests. Although Greene's dual-process theory is supported by an impressive body of evidence (Greene 2014b, pp. 700-708), it has attracted some criticism (Nagel and Waldmann 2013). Another response is to question the conclusion drawn from that premise: even if one grants that this account is correct, and agrees that people's moral responses are sensitive to irrelevant factors, it doesn't follow that the conflict between these responses should be resolved in a way that favors Singer's argument. Instead of concluding that we should save the child in both cases, one could conclude that we 
should save the child in neither case. To adjudicate between these two possibilities, a more sophisticated debunking argument would be required.

\section{Conclusion}

Singer's arguments for the conclusion that people in affluent societies - including academics reading these lines - have a strong moral obligation to donate much, if not most, of their resources to charitable organizations that prevent death and suffering pose a serious challenge to some of our deeply held moral convictions. Recent developments in the neuroscience and evolutionary psychology of morality have further increased the theoretical appeal of those arguments, both to psychologists interested in explaining our moral beliefs and to philosophers interested in vindicating or undermining their justification.

\section{Cross-References}

\author{
- Evolved Moral Foundations \\ - Moral Concerns \\ > Moral Instincts \\ - Morality Facilitates Cooperation \\ - Morality Is Cooperation
}

\section{References}

Ashford, E. (2011). Obligations of justice and beneficence to aid the severe poor. In P. Illingworth, T. W. Pogge, \& L. Wenar (Eds.), Giving well: The ethics of philanthropy (pp. 26-45). New York: Oxford University Press.
Bartels, D. M., Bauman, C. W., Cushman, F. A., Pizarro, D. A., \& McGraw, P. A. (2015). Moral judgment and decision making. In G. Keren \& G. Wu (Eds.), The Wiley-Blackwell handbook of judgment and decision making (pp. 478-515). Malden: Wiley-Blackwell.

GiveWell (2015, November). Mass distribution of longlasting insecticide-treated nets (LLINs). Retrieved from http://www.givewell.org/international/technical/ programs/insecticide-treated-nets\#Howcosteffectiveis LLINdistribution

Greene, J. D. (2014a). The cognitive neuroscience of moral judgment and decision making. In M. S. Gazzaniga \& G. R. Mangun (Eds.), The cognitive neurosciences (5th ed., pp. 1013-1023). Cambridge, MA: MIT Press.

Greene, J. D. (2014b). Beyond point-and-shoot morality: Why cognitive (neuro)science matters for ethics. Ethics, 124(4), 695-726.

Greene, J. D. (2016). Solving the trolley problem. In J. Sytsma (Ed.), A companion to experimental psychology (pp. 175-189). Hoboken: Wiley.

Kahane, G. (2011). Evolutionary debunking arguments. Noûs, 45(1), 103-125.

Kahneman, D. (2011). Thinking, fast and slow. New York: Farrar, Straus and Giroux.

Lewis, D. K. (2000). Illusory innocence? In Papers in ethics and social philosophy (pp. 152-158). Cambridge, UK: Cambridge University Press.

Nagel, J., \& Waldmann, M. R. (2013). Deconfounding distance effects in judgments of moral obligation. Journal of Experimental Psychology: Learning, Memory, and Cognition, 39(1), 237-252.

Singer, P. (1972). Famine, affluence, and morality. Philosophy \& Public Affairs, 1(3), 229-243.

Singer, P. (1999, September 5). The Singer solution to world poverty. The New York Times Magazine, pp. 60-63.

Singer, P. (2005). Ethics and intuitions. The Journal of Ethics, 9(3), 331-352.

Singer, P. (2009). The life you can save: Acting now to end poverty. New York: Random House.

Singer, P. (2011). Practical ethics (3rd ed.). Cambridge, UK: Cambridge University Press.

Sobel, D. (2007). The impotence of the demandingness objection. Philosophers' Imprint, 7(8).

Unger, P. K. (1996). Living high and letting die: Our illusion of innocence. New York: Oxford University Press. 